\title{
Physicochemical Characteristics of Citrus Seed Oils from Kerman, Iran
}

\author{
Mohammad Reazai, ${ }^{1}$ Issa Mohammadpourfard, ${ }^{1}$ Shahrokh Nazmara, ${ }^{2}$ \\ Mahdi Jahanbakhsh, ${ }^{1}$ and Leila Shiri ${ }^{2}$ \\ ${ }^{1}$ Department of Food Safety and Hygiene, School of Public Health, Tehran University of Medical Sciences, Tehran, Iran \\ ${ }^{2}$ Department of Environmental Health Engineering, School of Public Health, Tehran University of Medical Sciences, Tehran, Iran
}

Correspondence should be addressed to Shahrokh Nazmara; snazmara@gmail.com

Received 6 February 2014; Revised 28 June 2014; Accepted 30 June 2014; Published 17 July 2014

Academic Editor: Angel Catalá

Copyright ( 2014 Mohammad Reazai et al. This is an open access article distributed under the Creative Commons Attribution License, which permits unrestricted use, distribution, and reproduction in any medium, provided the original work is properly cited.

Recently, there has been a great deal of attention on usage, byproducts, and wastes of the food industry. There have been many studies on the properties of citrus seeds and extracted oil from citrus grown in Kerman, Iran. The rate of oil content of citrus seeds varies between $33.4 \%$ and $41.9 \%$. Linoleic acid $(33.2 \%$ to $36.3 \%)$ is the key fatty acid found in citrus seeds oil and oleic (24.8\% to $29.3 \%$ ) and palmitic acids (23.5\% to $29.4 \%$ ) are the next main fatty acids, respectively. There are also other acids found at trivial rates such as stearic, palmitoleic, and linolenic. With variation between $0.54 \mathrm{meg} / \mathrm{kg}$ and $0.77 \mathrm{mgq} / \mathrm{kg}$ in peroxide values of citrus seed oils, acidity value of the oil varies between $0.44 \%$ and $0.72 \%$. The results of the study showed that citrus seeds under study (orange and sour lemon grown in Kerman province) and the extracted oil have the potential of being used as the source of edible oil.

\section{Introduction}

Citrus species and 1300 of other species, classified in 140 genera, are members of the family Rutaceae. The fruit is grown mainly in south of Iran which is characterized with warm and humid climate, which is perfect for growing citrus [1]. Currently only the juice of the fruit is commercially used and the seeds are considered as waste. In general, peels, seeds, and pulps (around $50 \%$ of the fruit) are dealt with as wastes, while, potentially, they can be source of valuable byproduct [2]. Around 85 million ton (MT) of different types of citrus are the annual production of the world and Iran's contribution to this volume is $650.000 \mathrm{MT}$ (9\% of global production) [3]. The species of the fruit are found to be of medical values and are also used in confectionary, toiletry, and perfume industry. Given the economic, medical, and dietary values of citrus seed oil, there has been a recent surge of studies on the chemical composition (fatty acid content in particular) of the oil of seeds of different species of Citrus. Many works have measured the oil content of citrus seeds: Tunisian citrus seeds (26.1-36.1\%) [4], Brazilian Rangpur lime seeds (32.0-38.3\%)
[5], Egyptian citrus seeds (40.2-45.5\%) [6], Tunisian sweet orange (51.8\%) and lemon seeds (78.9\%) [4], and Pakistani citrus seeds (27.0-36.5\%) [7]. Taking into account the gravity of the subject under study and given the large number of similar studies in Iran, the present one measures the seed oils of more commonly found citrus fruits in Iran in an attempt to determine fatty acid composition of the neutral lipid classes of seed oils.

\section{Material and Methods}

Samples were collected from the citrus fruits grown in Kerman province, Iran, in September. The samples were sliced and the seeds were taken out, rinsed, and dried in oven ( $\left.40^{\circ} \mathrm{C}, 24 \mathrm{hrs}\right)$.

2.1. Reagents and Standards. Analytical grade chemical and solvent (Merck, Germany) were used in the study. In addition, pure standard FA methyl esters were obtained from Sigma Chemical Company. 
TABLE 1: Fatty acid compositions of the oils extracted from different citrus seed species (\%).

\begin{tabular}{|c|c|c|c|c|c|c|c|c|}
\hline & Palmitic & Palmitoleic & Stearic & Oleic & Linoleic & Linolenic & Other fatty acids & Oil content \\
\hline \multicolumn{9}{|l|}{ Qaleh Ganj } \\
\hline Lemon & 29.4 & 0.7 & 4.7 & 26.4 & 34.1 & 6.2 & 0.5 & 41.5 \\
\hline Citrus & 27.6 & 0.6 & 6.5 & 27.1 & 34 & 3.2 & 1 & 34.1 \\
\hline \multicolumn{9}{|l|}{ Jiroft } \\
\hline Lemon & 27.8 & 0.9 & 4.1 & 24.8 & 35.7 & 7 & 0.6 & 41.9 \\
\hline Citrus & 27.3 & 0.4 & 4.8 & 29.3 & 36.3 & 3.3 & 0.9 & 37.2 \\
\hline \multicolumn{9}{|l|}{ Anbarabad } \\
\hline Lemon & 23.5 & 0.6 & 4.2 & 28.5 & 33.7 & 7.8 & 1.4 & 40.3 \\
\hline Citrus & 26.5 & 0.6 & 6.5 & 28.6 & 32.2 & 4.1 & 1.5 & 33.4 \\
\hline
\end{tabular}

TABle 2: Physicochemical characteristics of oils from citrus seed species.

\begin{tabular}{lcccc}
\hline & $\mathrm{Iv}^{1}$ & $\mathrm{SN}^{2}$ & $\mathrm{PV}^{3}$ & $\mathrm{AV}^{4}$ \\
\hline $\begin{array}{l}\text { Qaleh Ganj } \\
\text { Lemon }\end{array}$ & 97.32 & 192.4 & 0.54 & 0.48 \\
Citrus & 99.65 & 189.2 & 0.63 & 0.52 \\
\hline Jiroft & & & & \\
$\quad$ Lemon & 98.17 & 191.3 & 0.55 & 0.44 \\
Citrus & 102.41 & 186.5 & 0.69 & 0.61 \\
\hline Anbarabad & & & & \\
Lemon & 100.38 & 187.6 & 0.77 & 0.72 \\
Citrus & 103.77 & 188.9 & 0.64 & 0.58 \\
\hline
\end{tabular}

${ }^{1}$ Iodine value (I2 g per $100 \mathrm{~g}$ of oil).

${ }^{2}$ Saponification number (mg KOH per g of oil).

${ }^{3}$ Peroxide value (mequiv $\mathrm{O}_{2}$ per $\mathrm{kg}$ of oil).

${ }^{4}$ Acid value (mg KOH per g of oil).

2.2. Oil Extraction. About 100 gr of crushed and grounded seeds (powder) was put into Soxhlet extractor with $1 \mathrm{Li}$ bottomed flask and a condenser. During 8 hrs of extraction, $0.5 \mathrm{Li}$ of hexane and n-hexane was extracted at $40^{\circ} \mathrm{C}$ or less with a rotator vacuum evaporator [8].

2.3. Preparation of Fatty Acid Methyl Esters (FAMEs). In preparation of methyl esters fatty acid form the seeds, AOCS official method was followed [9].

2.4. Fatty Acids Detection. By transforming fatty acids into FAMEs by GC (Unicam 4600, UK) attached with a flame ionization capillary column fused silica $(30 \mathrm{~m} \times 0.25$ (I.D.) mm, film thickness: $0.22 \mu \mathrm{m}$ ), FA composition was studied. As gas carrier, helium was used. Then the temperature of the sample was increased up to $180^{\circ} \mathrm{C}$ at $20^{\circ} \mathrm{C} / \mathrm{min}$ and it remained at this temperature for $10 \mathrm{~min}$ and afterward, with the same rate, the temperature was increased to $210^{\circ} \mathrm{C}$. Temperature of the detector and injector was set at $250^{\circ} \mathrm{C}[10]$.

2.5. Other Properties. Saponification value, acid value, iodine value, and peroxide value were determined according to AOAC 2005 [11].

\section{Results}

Table 1 lists the composition of fatty acid and fat content of citrus seeds. As the results show, the oil content ranges between $40.3 \%$ and $41.9 \%$ for sour lemon and $33.4 \%$ and $34.2 \%$ for orange. The mostly found saturated component in all citrus seeds is palmitic acid. Its content varies for different types of seeds and on average it ranges between $26.9 \%$ in sour lemon seed and $27.13 \%$ in organ seed. In addition, the content of oleic acid of sour lemon was found between $24.8 \%$ (samples from Jiroft) and 28.5\% (samples from Anbarabad) and in the case of orange it was found between $27.1 \%$ (samples from Qaleh Ganj) and 29.3\% (samples from Jiroft). The content of linoleic acid, also, ranged between $33.7 \%$ and $36.3 \%$ and $32.3 \%$ and $36 \%$ for sour lemon and orange, respectively. The rest of the properties of the seeds are listed in Table 2. As indicated, average amount of iodine, peroxide, acid, and saponification in sour lemon is $98.62 \%, 0.62 \%, 0.54 \%$, and $190.43 \%$; these figures for orange are $101.94 \%, 0.65 \%, 0.57 \%$, and $188.2 \%$, respectively.

\section{Discussion}

The considerable content of unsaturated fatty acid in oil of the seeds hints at the great nutritional value of the oil so that linoleic acid is one of the 3 essential FAs. In comparison, the oil of sour lemon seeds is the best option regarding unsaturated fatty acid (nutritional value). Regarding the composition of the oil from different species and varieties, this study found the samples less different comparing with the results of other similar studies. Researches that have been conducted on properties of citrus seed oils are as follows. Anwar et al. found that linoleic acid is the main acid in citrus seed oil (36.1-39.8\%) and the other key fatty acids were palmitic acid (25.8-32.2\%), oleic acid (21.9-24.1\%), linolenic acid (3.4-4.4\%), and stearic acid (2.8-4.4\%) [7]. In a study by Matthaus and Ozcan, the oil content of seeds was reported somewhat between $32.1 \mathrm{~g} / 100 \mathrm{~g}$ and $58.8 \mathrm{~g} / 100 \mathrm{~g}$. In descending order, the main fatty acids in the oil samples were oleic (12.8-70.1\%), linoleic (19.5-58.8\%), and palmitic (5.1$28.3 \%)$. Furthermore, content of stearic, vaccenic, linolenic, and arachidic acids was negligible [12]. Mahmud et al. reported good quality of unsaturated acids found in citrus fruit oil (49.92\%). Such high content of unsaturated acid 
is expected in a quality edible oil [13]. In another study, Saloua et al. indicated that linoleic $(76.19 \%)$, oleic $(13.87 \%)$, stearic $(6.76 \%)$, and palmitic acids $(2.40 \%)$ are the key fatty acids found in crude oil [14]. Waheed et al. showed that, in sum, content of lipids C18:3 was $4.66 \%$ in C. aurantium and $3.58 \%$ in C. paradisi [15]. Our results are similar in fatty acid composition when compared to the values in the literature. As the results discussed herein showed, orange and sour lemon seeds oil is a rich source of unsaturated fatty acids so that citrus seed oil can be of the best oils for man.

\section{Conclusion}

Nutritionally speaking, citrus seed oil is a notable choice so that average unsaturated fatty acids found in sour lemon and orange varieties are $66.46 \%$ and $68.83 \%$, respectively. Our results indicated that the oil extracted from citrus seeds grown in Iran is a rich source of essential fatty acids and is of high potential for being used for nutritional and industrial usages. As one of the biggest producers of sour lemon and orange, the seeds of the fruits in Iran, which are currently disposed of, can be a reliable source of edible oil.

\section{Conflict of Interests}

The authors declare that there is no conflict of interests regarding the publication of this paper.

\section{References}

[1] I. A. Khan, Citrus Genetics, Breeding and Biotechnology, CABI, 2007.

[2] T. A. El-Adawy, E. H. Rahma, A. A. El-Bedawy, and A. M. Gafar, "Properties of some citrus seeds. Part 3. Evaluation as a new source of protein and oil," Food/Nahrung, vol. 43, no. 6, pp. 385391, 1999.

[3] S. H. Vand and T. L. Abdullah, "Identification and introduction of thornless lime (Citrus aurantifolia) in Hormozgan, Iran," Indian Journal of Science and Technology, vol. 5, no. 11, pp. 36703673, 2012.

[4] M. Saïdani, W. Dhifi, and B. Marzouk, "Lipid evaluation of some Tunisian Citrus seeds," Journal of Food Lipids, vol. 11, no. 3, pp. 242-250, 2004.

[5] S. Y. Reda, E. S. Leal, E. A. C. Batista et al., "Characterization of rangpur lime (Citrus limonia Osbeck) and "sicilian" lemon (Citrus limon) seed oils, an agroindustrial waste," Ciência e Tecnologia de Alimentos, vol. 25, no. 4, pp. 672-676, 2005.

[6] M. A. Habib, M. A. Hammam, A. A. Sakr, and Y. A. Ashoush, "Chemical evaluation of egyptian citrus seeds as potential sources of vegetable oils," Journal of the American Oil Chemists'Society, vol. 63, no. 9, pp. 1192-1196, 1986.

[7] F. Anwar, R. Naseer, M. I. Bhanger, S. Ashraf, F. N. Talpur, and F. A. Aladedunye, "Physico-chemical characteristics of citrus seeds and seed oils from Pakistan," Journal of the American Oil Chemists' Society, vol. 85, no. 4, pp. 321-330, 2008.

[8] Q. A. Zhang, Z. Zhang, X. Yue, X. Fan, T. Li, and S. Chen, "Response surface optimization of ultrasound-assisted oil extraction from autoclaved almond powder," Food Chemistry, vol. 116, no. 2, pp. 513-518, 2009.
[9] AOCS, Official Methods and Recommended Practices of the American Oil Chemists'Society, vol. 6, AOCS, Champaign, Ill, USA, 2009.

[10] A. Moayedi, K. Rezaei, S. Moini, and B. Keshavarz, "Chemical compositions of oils from several wild almond species," Journal of the American Oil Chemists' Society, vol. 88, no. 4, pp. 503-508, 2011.

[11] AOAC, Association of Official Analytical Chemists, vol. 18, AOAC International, Gaithersburg, Md, USA, 2005.

[12] B. Matthaus and M. M. Ozcan, "Chemical evaluation of citrus seeds, an agro-industrial waste, as a new potential source of vegetable oils," Grasas y Aceites, vol. 63, no. 3, pp. 313-320, 2012.

[13] S. Mahmud, H. Akhtar, M. Saleem, and R. Khanum, "Lipid classes of in vitro cultivar of Pakistani citrus," Journal of Saudi Chemical Society, vol. 13, no. 3, pp. 299-302, 2009.

[14] F. Saloua, N. I. Eddine, and Z. Hedi, "Chemical composition and profile characteristics of Osage orange Maclura pomifera (Rafin.) Schneider seed and seed oil," Industrial Crops and Products, vol. 29, no. 1, pp. 1-8, 2009.

[15] A. Waheed, S. Mahmud, M. Saleem, and T. Ahmad, "Fatty acid composition of neutral lipid: classes of Citrus seed oil," Journal of Saudi Chemical Society, vol. 13, no. 3, pp. 269-272, 2009. 

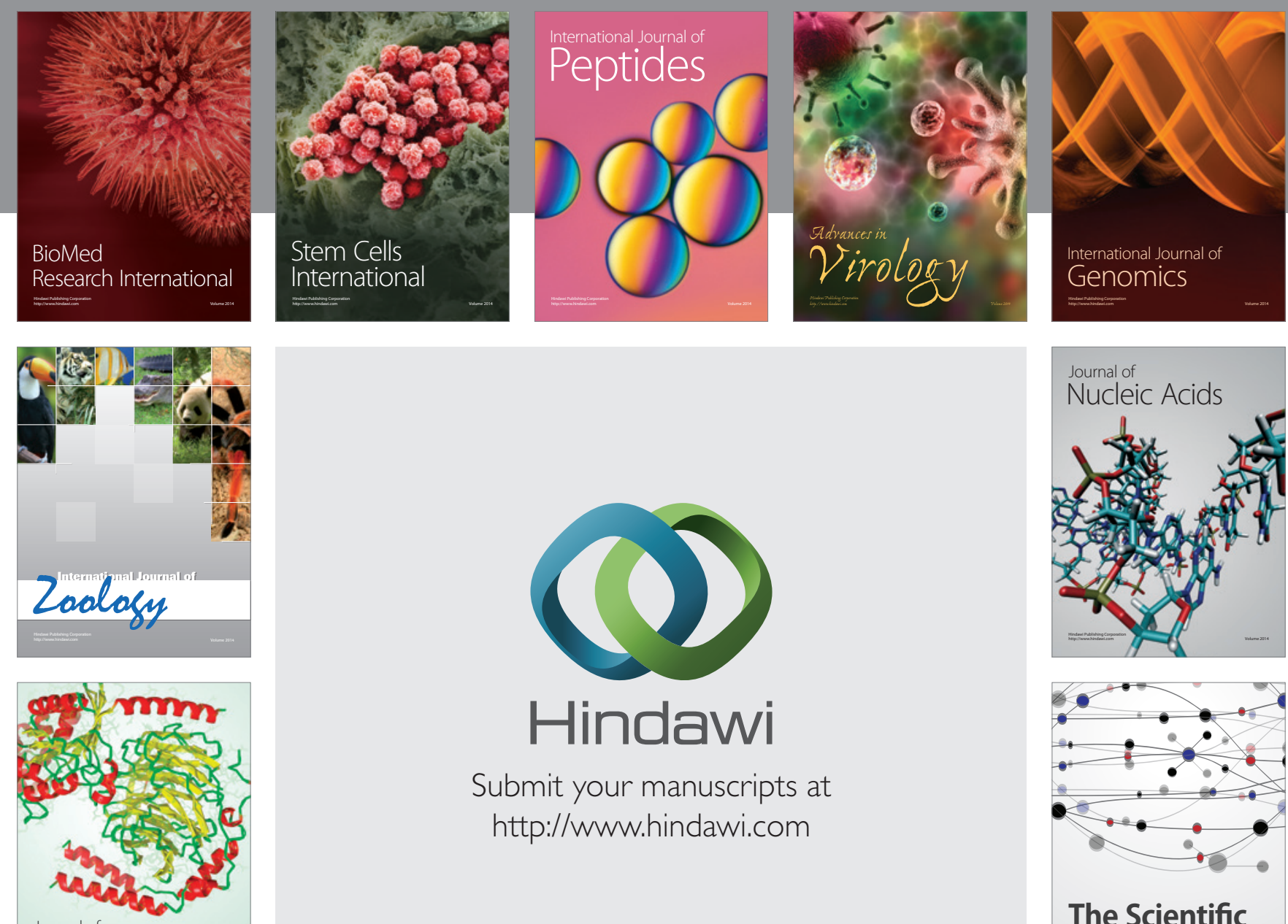

Submit your manuscripts at

http://www.hindawi.com

Journal of
Signal Transduction
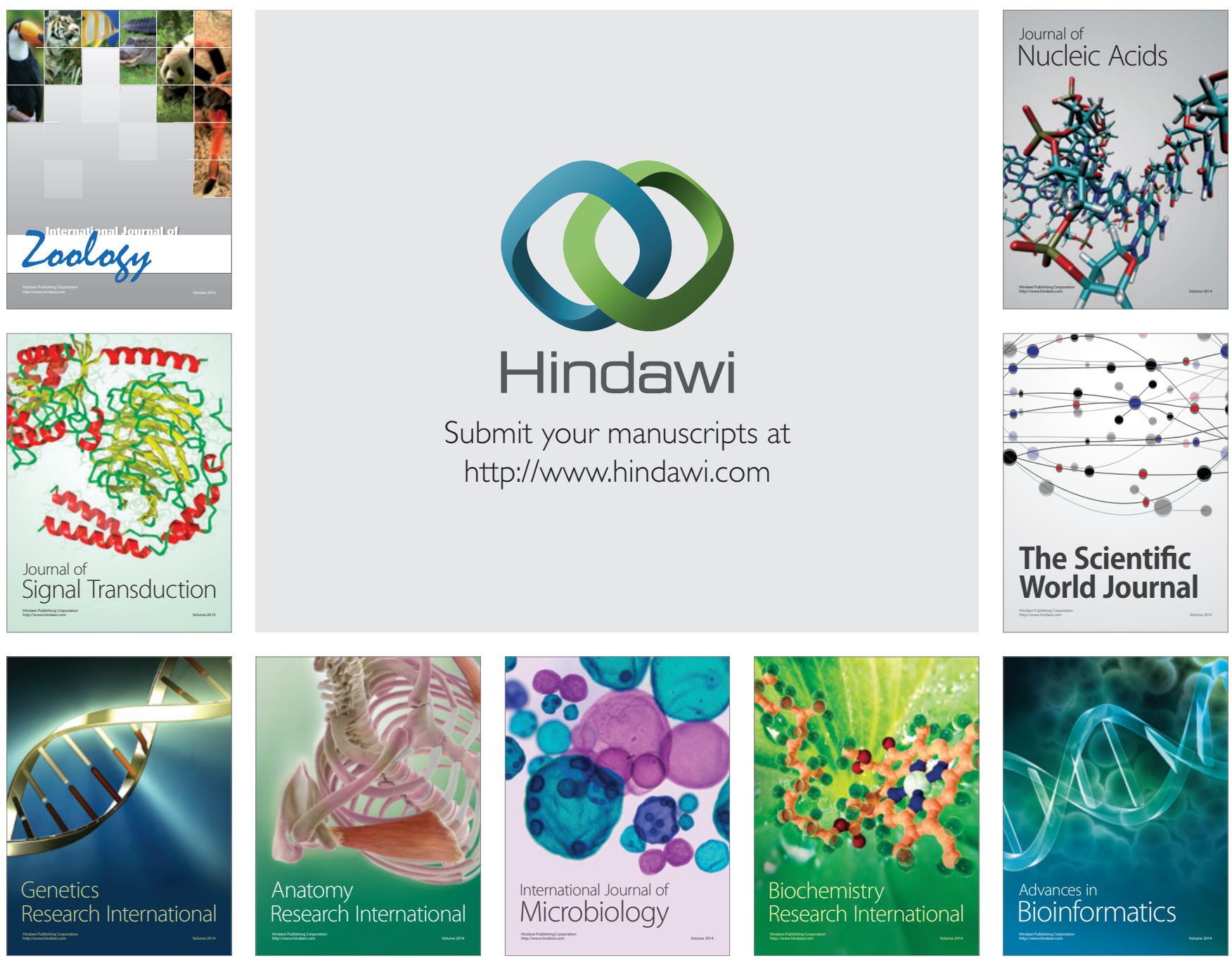

The Scientific World Journal
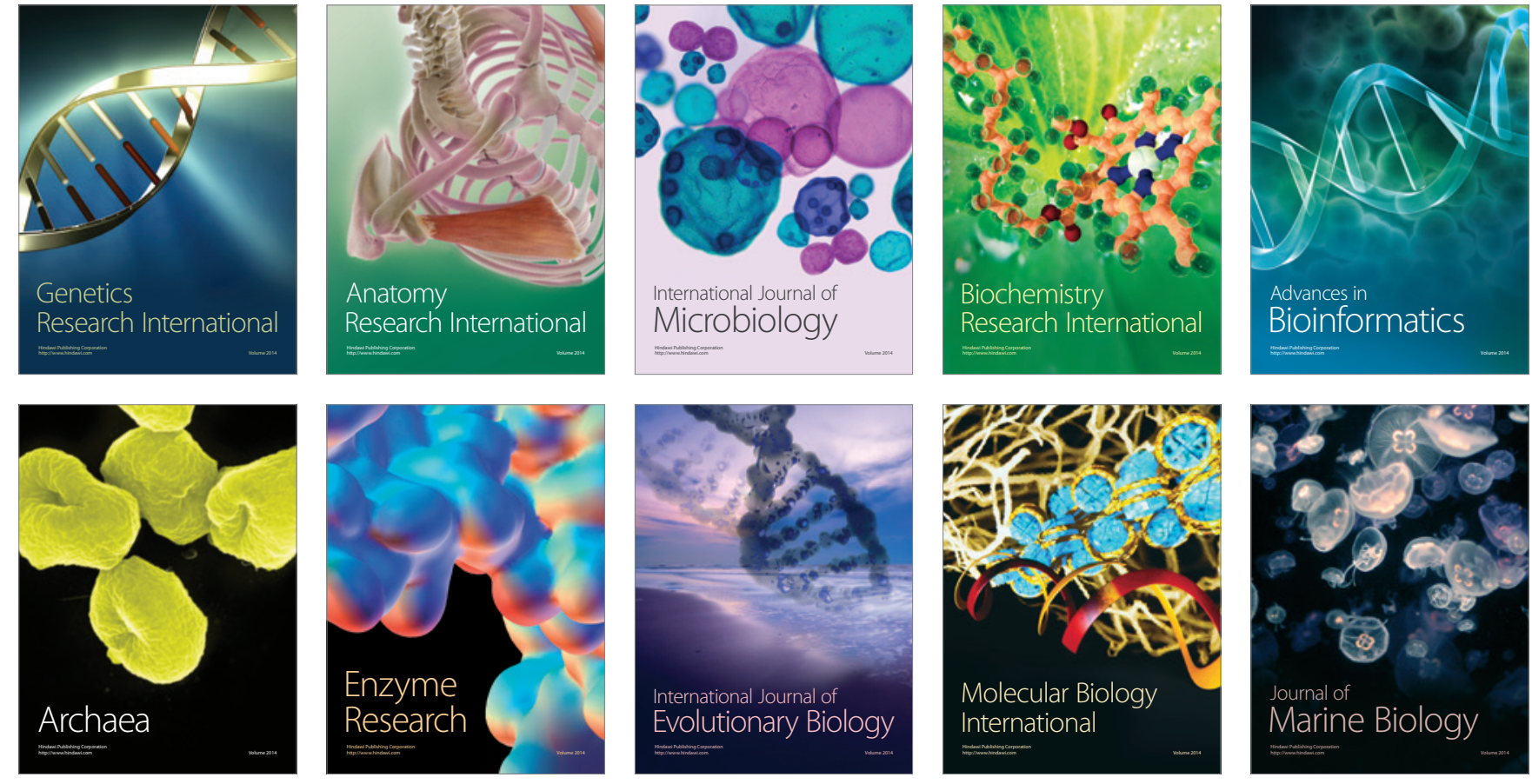